\title{
The Effects Of Technology Readiness And Technology Acceptance On NFC Mobile Payment Services In Korea
}

Seungjae Shin, Mississippi State University, USA Won-jun Lee, Cheongju University, Korea

\begin{abstract}
The Near Field Communication (NFC) mobile payment is the integration of NFC enabled smartphones and credit/debit/prepaid cards. Korea is a pioneer in rolling out the NFC mobile payment. Global mobile industries pay attention to whether Korean mobile users accept the new payment service. This study investigates the factors for technology acceptance using an integrated model of technology readiness and technology acceptance. Structured equation modeling is used to analyze the collected data. The four constructs of technology readiness (innovativeness, optimism, discomfort, and insecurity) have significant impact on the perceived ease of use and the two technological characteristics of NFC mobile payment (responsiveness and smartness) also have significant impacts on the perceived usefulness. However, only the perceived usefulness affects significantly on the intention to use. The perceived ease of use affects indirectly on the intention to use through the perceived usefulness. The result of this study suggests that to be a successful payment service, the NFC mobile payment service has to be much more focused on the usefulness against other alternative payment methods.
\end{abstract}

Keywords: Near Field Communications; Mobile Payment; TAM; Technology Readiness

\section{INTRODUCTION}

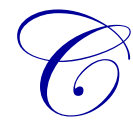

ell phones and related services have become a crucial part in daily life. Since Apple's iPhone was introduced in 2007, mobile phones have been replaced by smartphones. A smartphone is a good example of digital convergence because a smartphone is an integrated mobile device of calling features and internet access. With an introduction of mobile TV service in Korea in 2005 (Shim, Shin, \& Weiss, 2006), such as digital mobile broadcasting (DMB), a smatphone is a mobile version of triple convergence of voice, TV and internet services. One of the recent new functions of a smartphone is mobile banking and shopping. With the development of wireless broadband technologies such as 3G/4G, WiMAX, and WiFi; smartphone users have moved from internet banking/shopping to mobile banking/shopping. Mobile payment is a critical component of mobile transactions. Mobile payment is defined as "a transfer of funds for goods or services in which a mobile device is functionally involved in executing and confirming payment" (Smart Card Alliance, 2011). The mobile payment is classified into two forms: remote payment or proximity payment (Agarwal et al., 2007): In the remote mobile payment, customers and sellers are at different locations; in the proximity mobile payment, customers and sellers are in the same location. There are five components in a mobile payment system: a payer and a payee, a financial service provider (FSP), a payment service provider (PSP), and a mobile network operator (MNO). The FSP is banks / credit card issuing companies, and the MNO is wireless carriers. The PSP is companies taking care of communications between the FSP and the payer/payee, which is usually called trusted service manager (Smart Card Alliance, 2011). While the remote mobile payment is supported by the traditional wireless broadband technology, the proximity mobile payment is made by a relatively new short-range wireless technology, i.e. Near Field Communications (NFC). While a customer sends a payment request to the PSP through wireless network in the remote mobile payment, the customer directly sends a payment request to the payee's POS terminal through NFC technology in the proximity payment. 
A user's mobile phone with NFC technology could be a mobile wallet, which includes all financial information about credit cards, bank accounts, loyalty cards, and prepaid cards. The mobile phone acts as a credit/debit card, not by swiping the phone, but by tapping or just approaching card reader terminals. The mobile wallet technology is due to the fact that there is a high demand for smartphones and that consumers are always in possession of their mobile devices and financial cards. Because the mobile wallet technology allows readers to capture this financial information simultaneously, the NFC mobile payment could give smartphone users dramatic conveniences. VISA PayWave and MasterCard PayPass are prepaid cards with NFC technology, which are known as contactless smart cards. According to Meijer and Bye (2011), the reasons to choose NFC mobile payment instead of contactless smart cards, are convenient to use it without a PIN or a signature or issuing a paper receipt, which will reduce a waiting time in checkout lines. In addition to convenience, it is a technology of real-time transactions and two-way communications and it shows a history of transaction and current balances, which improve smartphone users' ability for interactivity and intelligence. Google wallet is an example of both proximity and remote mobile payment systems, which was introduced in 2011. Google wallet is associated with debit/credit MasterCard cards. Google wallet can also be used for online shopping with a mobile app and it can send/receive money with an e-mail (Shin, Lee, and Odom, 2014).

According to OECD's statistics for information and communication technology (http://www.oecd.org), in 2013, Korea has $105 \%$ of mobile service penetration rate and $103 \%$ of wireless broadband service penetration rate, which means every Korean mobile users uses wireless internet service as a necessary service. According to the 2013 report of Google's "Our Mobile Planet" project (http://think.withgoogle.com/mobileplanet/en/), smartphone penetration in Korea is $56 \%$ and $46 \%$ of the smartphone users have experienced purchasing on their smartphone. According to the Nielsen's report about mobile consumers (2013), Korea has the highest smartphone penetration rate $(67 \%)$ in their survey. According to the Credit Finance Association of Korea (http://www.crefia.or.kr), the number of credit cards owned by the average economically active Korean is 4.8, as of March 2012. The high adoption of smartphones and credit card usage in Korea has led for online banking and online shopping consumers to transition into using their smartphones for mobile banking and mobile shopping.

Mobile payment originates from SMS text messaging, which is supported by the $2 \mathrm{G}$ mobile technology (Shin, et al., 2014). SMS mobile payment is a way to make the user's cellular phone a payment tool through text messaging. Mobile users can send a payment request through the SMS messaging and the premium charge is applied to their phone bill. With the advent of $3 \mathrm{G}$ mobile technology, users started to conduct internet banking with their internet enabled mobile devices. As the $3 \mathrm{G}$ technology gains popularity, banks and online merchants redesign their websites to be accessible by mobile devices. This method is very similar as internet banking / internet payment and mobile users use wireless internet access for their payment. The banking industry in Korea provides a digital certificate for the online banking users for free. The personal digital certificate has to be saved on a personal smartphone. Without buying a hardware authentication token, online banking users in Korea are able to use their own smartphone for their authentication in Korea. The free online certificate is a booster for high rate of mobile payment in Korea. Korean smartphone users have used their smartphones to pay bus and subway fares. T-Money is a pre-paid radio frequency based smartcard which is embedded with a CPU that enables calculation on the card (Ezell, 2009). Korean commuters using public transportation could pay fees with Mobile T-Money, which is TMoney on the commuters' smartphone using their SIM card. Mobile T-Money can also be transferred between accounts as forms of payment.

To promote NFC mobile payments in Korea, the Grand NFC Korea Alliance was established in 2011, which included three major Korean mobile service providers and nine major credit card issuers (Brown, 2011). The Korea Communications Commission (KCC), a media regulation government agency, has been a leader in promoting this project. After the three month pilot project in the busiest shopping streets of the capital city, the NFC mobile payment project was expanded nationally as of February 2012. Since then, the major Korean smartphone makers have produced their smartphones with the NFC technology, and major retailers and service providers have installed NFC readers in their stores. However, there is a $\$ 300$ limit for each transaction.

Accordingly, NFC mobile payment technology is expected to change consumers' behaviors in dealing with financial service sectors and to create new business opportunities for companies. Therefore, research on this issue is important in understanding consumer and market strategy from the consumer's point of view. In recent years, there 
has been an increase in research concerned with issues of mobile banking; however, NFC related issues were rarely studied without any empirical results as of yet. The purpose of this study is to examine the individual technology readiness of the consumer and the characteristics of the NFC mobile payment technology contributing to the NFC mobile payment user's acceptance.

The paper is organized in the following order: In the next section, the authors explore the theoretical background for this research. In the third section, the authors discuss the nine hypotheses used in the model. In the fourth section, methodology is analyzed and in the fifth section the results are presented. The conclusion and discussion section is added at the end.

\section{THEORETICAL BACKGROUND}

The Technology Acceptance Model (TAM) proposed by Fred David could explain new technology use based on users' motivations, which are influenced by external stimuli such as the technology's characteristics and capabilities (Chuttur, 2009). Davis (1989) suggests that three factors, perceived ease of use, perceived usefulness, and attitude toward using the technology, have an influence on users' motivation, which determines their intention to use. Davis (1989) believes that perceived usefulness and perceived ease of use are the two factors that determine the attitude toward behavioral intention. While the perceived usefulness is related to the belief that use of the technology will improve users' performance, perceived ease of use is explained by a level of easiness in using the technology (Ha and Stoel, 2009). Perceived ease of use is expected to influence perceived usefulness and perceived usefulness is the strongest determinant in the TAM model. David suggests that other external variables need to be tested for the relationship with perceived usefulness and perceived ease of use.

Parasuraman and Colby (2000) suggest technology readiness (TR), which has four personal beliefs about acceptance of new technology. TR refers to "people's propensity to embrace and use new technologies for accomplishing goals in home life and at work" and it can be measured by using TR constructs, comprising for four personality sub-dimensions: optimism, innovativeness, discomfort, and insecurity. They define innovativeness as, "a tendency to be a technology pioneer and thought leader", optimism as, "a positive view about the technology", discomfort as, "a feeling of being overwhelmed by the technology", and insecurity as, "distrust of the technology". In general, optimism and innovativeness are positive drivers of new technology acceptance, while discomfort and insecurity hinder new technology acceptance.

New approaches have been made by integrating the above two models (Lin, Shih, \&Sher, 2007). Technology Readiness and Acceptance Model (TRAM) is an augmented model with TAM and TR. According to Lin et al. (2007), there are theoretical and practical bases to insist that when people evaluate their intentions to adopt a new technology, cognitive information of technology readiness is retrieved before they perceive usefulness and ease of use. Also, technology readiness has very close relationships with self-efficacy (Venkatesh and Davis 1996) and perceived control (Kang et al. 2006). Both concepts are all about one's perception toward one's capability to use technologies easily.

Some researchers, who examine mobile payment consumer behavior, have approached the problem by using technology acceptance theories (Schierz, 2010; Liu et al. 2011; Stalfors and Nykvist, 2011; Meharia, 2012). Most researches with TRAM make a model of dual paths under the assumption that the four TR constructs have an influence to both perceived ease of use and perceived usefulness. However, Venkatesh and Davis (1996) finds in their experiments that usability and self-efficacy are two main factors for ease of use perception and Venkatesh (2000) finds that control, intrinsic motivation, and emotion determine early perception about the ease of use of a new system. In addition, Ma and Liu (2004) analyze 26 empirical studies of TAM and find that the relationship between perceived ease of use and technology acceptance is weak and perceived ease of use impact on technology acceptance through perceived usefulness. Therefore, authors assume that technology readiness, which is based on prior product experience and knowledge, will mainly affect perceived ease of use rather than perceived usefulness. The authors also assume that perceived usefulness will be affected by characteristics of technology. 


\section{HYPOTHESIS DEVELOPMENT}

\subsection{Components of TR}

The generalized beliefs about technology that are formed through prior experience with a product could guide the information processing of the consumer, including interpreting and integrating information to make judgments (Lin et al. 2007). It is known that customers thinking optimistically and innovatively about a new technology have tendencies to express positive attitudes toward new technology. Optimism and innovativeness are two enablers of technology readiness (Godoe and Johansen, 2012). Lam, Chiang, \& Parasuraman (2008) find that there is a positive relationship between consumer innovativeness and people's attitudes toward using internet service. It is known that there is a positive relationship between optimism and perceived ease of use (Walczuch, Lemmink, and Streukens, 2007). Godoe and Johansen (2012) also find that innovativeness and optimism significantly influence perceived ease of use when using an electronic health record system. The hypothesis H1 and $\mathrm{H} 2$ are related with innovativeness and optimism.

H1. Innovativeness has a positive effect on a consumer's perceived ease of use of NFC payment.

H2. Optimism has a positive effect on a consumer's perceived ease of use of NFC payment.

It is also known that discomfort and insecurity account for negative attitudes toward new technology and they are two inhibitors of technology readiness (Godoe and Johansen, 2012). Lam et al. (2008) find that discomfort has a negative effect on the length of time it takes for a consumer to accept the internet and ease of use of the internet. Godoe and Johansen (2012) found that there is a negative relationship between discomfort and perceived ease of use. The mobile payment process could be perceived as a high risk task to consumers and security has been one of the key issues in online commerce and mobile financial services (Hsu et al. 2011). Three components of the security principle are confidentiality, integrity, and availability, which are called the CIA triad. In addition, authenticity and non-repudiation are required for secure or risk-free transactions. Many previous TAM studies add perceived security or perceived risk as a TAM construct with perceived usefulness and perceived ease of use (Meharia, 2012). Schierz (2010) and Meharia (2012) find that there is a positive link between perceived security and attitude toward using mobile payment systems. Therefore, the security issue is highly important to consumers who want to use new technology, especially financial transaction systems. In many previous research studies, it is believed that insecurity affects consumer attitudes negatively (Walczuch et al. 2007; Lam et al. 2008). The perception of insecurity has been, and will continue to be, a barrier to adoption of new technology (Varshney and Vetter 2002). Moon and Kim (2001) indicate that there is a close relationship between perceived ease of use and a user's perception of security. However, the authors believe that insecurity has a positive relationship with ease of use in NFC mobile payment services. Most of the NFC mobile payment users have experienced credit/debit cards which have been considered as a secure transaction method. Because NFC mobile payment is the integration of credit/debit cards, users already have trust in using their credit/debit cards, which are imbedded in their smartphone. In addition, because the smartphone is also a hand-held computer, it needs to update software patches for improving security in using their smartphone in financial transactions. Before using mobile payment sites, multiple downloadings (figure 1) are pre-requisites such as firewall modules, cryptographic system modules, and keyboard security modules, which are online financial transaction standards in Korea. Authentication is another important check for mobile payment in Korea, which requires requesting a registered PIN number or scanning fingerprints. Security code matrix card (figure 1) and several passwords for account, digital certificate, and transfer, are mandatory inputs for a safe mobile payment. This is an issue for growth of Korean e-commerce companies because the tight control for secure transaction is good for domestic users but it is almost impossible for foreign users because personal presence is needed to have the security code matrix card. Therefore, the relation between insecurity and ease of use can be explained in two ways. First, the more security software updates proves that there are underlying flaws in the service. Second, good security often takes a while to fully check user's authentication. These two often cause discomfort and unease to use. Therefore, in Korea, security gives a negative effect to ease of use because of its complicated procedure for mobile payment. Therefore, insecurity is assumed to give a positive effect to ease of use. The hypothesis $\mathrm{H} 3$ and $\mathrm{H} 4$ are related to discomfort and insecurity. 
H3. Discomfort has a negative effect on a consumer's perceived ease of use of NFC payment.

H4. Insecurity has a positive effect on a consumer's perceived ease of use of NFC payment.
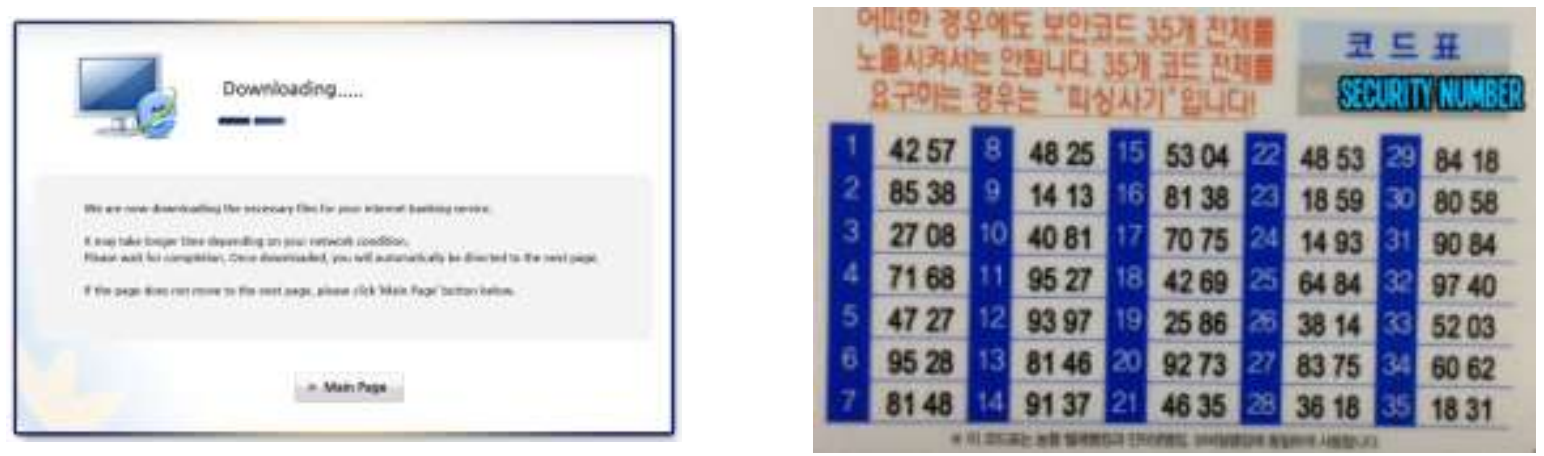

Figure 1: Software Downloading And Security Code Matrix Card For Financial Transactions

\subsection{Components of Technology Characteristics}

Responsiveness is one of the most important characteristics of Human-Computer Interaction (HCI). Mobile users expect that the NFC mobile payment system to be responsive to the users' requests and using NFC mobile payment systems seem to be smart and modern. Oblinger and Oblinger (2005) tell in their book that responsiveness is one of the important factors to attract net generation. Kim and Ammeter (2008) also argue that responsiveness is strongly associated with intention to use of online shopping. Chang and Wang (2008) find that interactivity, similar concept of responsiveness, had a great effect on perceived usefulness in consumer's web activity. Rijsdijk and Hultink (2009) find that product smartness increases perceived relative advantage and the relative advantage positively influences the rate of adoption. Warshaw and Davis (1985) insist that people tend to use a system to the extent that they believe it will help them perform their jobs better. As a result, a smart system shows people that the system is useful. Therefore, responsiveness and smartness are assumed as two main characteristics of NFC mobile payment technology that influence the perceived usefulness. The hypothesis $\mathrm{H} 5$ and $\mathrm{H} 6$ are related to responsiveness and smartness when consumers responses to new smart products with application of information technology.

H5. Responsiveness has a positive effect on a consumer's perceived usefulness of NFC payment.

H6. Smartness has a positive effect on a consumer's perceived usefulness of NFC payment.

\subsection{Components of TAM}

In TAM, behavioral intention to use the system is determined by a user's adoption attitude, which consists of perceived ease of use and perceived usefulness. Chen (2008) insists that individual beliefs such as usefulness and ease of use can predict the extent to which users will use a mobile payment system. In many researches testing acceptance of mobile applications, the relationship between perceive usefulness and behavioral intention is supported (Hsu et al. 2011). In addition, perceived ease of use is also assumed to influence perceived usefulness, which is based on the idea that improved ease of use can contribute to increase usefulness (Davis, et al, 1989). The hypothesis $\mathrm{H} 7, \mathrm{H} 8$ and $\mathrm{H} 9$ are related to perceived ease of use and perceived usefulness.

H7. Perceived ease of use has a positive effect on perceived usefulness.

H8. Perceived ease of use has a positive effect on a consumer's intention to use NFC payment.

H9. Perceived usefulness has a positive effect on a consumer's intention to use NFC payment. 
Figure 2 represents the research model and its hypotheses used in this study. Among the nine hypotheses, all of them except $\mathrm{H} 3$ are assumed to be a positive effect.

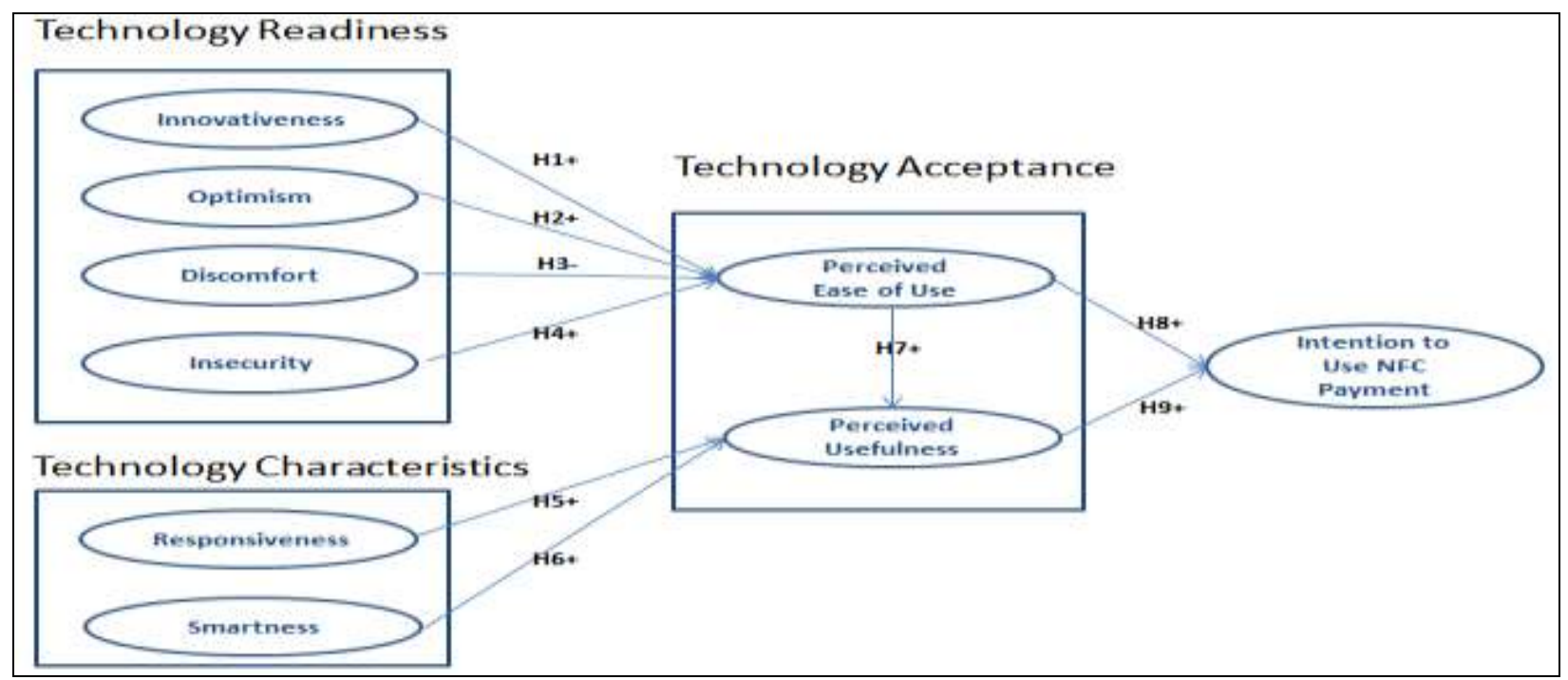

Figure 2: Research Model And Hypothesis

\section{RESEARCH METHOD}

\subsection{Measure Development}

Due to the relative scarcity of empirical research on the mobile payment service of NFC technology, this study's intention is to introduce an initial NFC mobile payment service acceptance model. Measures of the constructs are developed in several stages. Based on the defined constructs, all measures are borrowed from the existing literatures. The authors measure the TR construct using the 12-item TR scale, which is based on the paper by Lam et al. (2008). The NFC mobile payment service's characteristics are consisted of responsiveness and smartness. The three items for responsiveness measurement originate from the paper by Banwari and Lassar (1996) and the three items for smartness measurement originate from the paper by Pechmman and Ratneshwar (1994). The TAM consists of perceived ease of use and perceived usefulness, each of which has three items based on the paper of mobile financial service by Hsu, Wang, and Lin (2011). Behavioral intention to use NFC mobile payment is measured with the three items from Venkatesh and Goyal (2010). All 27 items are translated into Korean and back translation is used to check whether both versions of items were identical. Table 1 provides a list of all measurement items. 
Table 1: Measurement Items

\begin{tabular}{|c|c|}
\hline Constructs & Items \\
\hline \multirow{3}{*}{ Innovativeness } & (C1) In general, I am among the first in my circle of friends to acquire new technology when it appears. \\
\hline & (C2) I can usually figure out new high-tech products and services without help from others. \\
\hline & (C3) I enjoy the challenge of figuring out high-tech gadgets. \\
\hline \multirow{3}{*}{ Optimism } & (C4) Technology gives people more control over their daily lives. \\
\hline & (C5) Technology makes me more efficient in my occupation. \\
\hline & (C6) Technology gives me more freedom of mobility. \\
\hline \multirow{3}{*}{ Discomfort } & (C7) Technical support lines are not helpful because they don't explain things in terms I understand. \\
\hline & (C8) Sometimes I think that technology systems are not designed for use by ordinary people. \\
\hline & (C9) There is no such thing as a manual for a high-tech product or service that's written in plain language. \\
\hline \multirow{3}{*}{ Insecurity } & (C10) I do not consider it safe giving out a credit card number over a computer. \\
\hline & (C11) I do not consider it safe to do any kind of financial business online. \\
\hline & (C12) I worry that information I send over the Internet will be seen by other people. \\
\hline \multirow{3}{*}{ Responsiveness } & (C13) NFC mobile payment will offer prompt service to me. \\
\hline & (C14) NFC mobile payment has willingness to help me. \\
\hline & (C15) NFC mobile payment gives me individual attention. \\
\hline \multirow{3}{*}{ Smartness } & (C16) NFC mobile payment is intelligent. \\
\hline & (C17) NFC mobile payment is smart. \\
\hline & (C18) NFC mobile payment makes me look smart. \\
\hline \multirow{3}{*}{$\begin{array}{l}\text { Perceived Ease } \\
\text { of Use }\end{array}$} & (C19) Learning to operate an NFC mobile payment system would be easy for me. \\
\hline & (C20) I would find an NFC mobile payment system easy to use. \\
\hline & (C21) I think it is easy to use an NFC mobile payment system. \\
\hline \multirow{3}{*}{$\begin{array}{l}\text { Perceived } \\
\text { Usefulness }\end{array}$} & $\begin{array}{l}\text { (C22) Using NFC mobile payment system in my finance related job would enable me to accomplish tasks } \\
\text { more quickly. }\end{array}$ \\
\hline & (C23) Using NFC mobile payment would enhance the effectiveness of my finance related job. \\
\hline & (C24) I would find NFC mobile payment system useful in my finance job. \\
\hline \multirow{3}{*}{$\begin{array}{l}\text { Intention to } \\
\text { Use }\end{array}$} & (C25) I intend to use the NFC mobile payment system. \\
\hline & (C26) I predict I would continue using the NFC mobile payment system. \\
\hline & (C27) I plan to continue using the NFC mobile payment system. \\
\hline
\end{tabular}

\subsection{Sample}

Data is collected from personal interviews with college students in Korea. Survey questions were based on a Likert 7-point scale: 1 (strongly disagree) through 7 (strongly agree). On the first page of the questionnaire, a short description of NFC mobile payment service is explained. Research participants are instructed to read the explanation completely before moving onto the next page. The 585 samples are drawn from metropolitan areas of Korea, who have experienced smartphone service. The average age of respondents is 23.8 years old with standard deviation of 2.02. $52.5 \%$ of them are male students and $47.5 \%$ are female students.

\subsection{Reliability and Validity of Measures}

Reliable and valid measurement of the each factor are tested through coefficient alphas, composite reliabilities, and average variances extracted (AVE). Cronbach's alpha is most commonly used as an estimate of reliability. Internal consistency is initially assessed by computing Cronbach's alpha. Each coefficient alpha of eight individual factors, except for discomfort (.626), exceeds the Nunnally's recommended threshold of .7 (table 2). Exploratory factor analysis (EFA) is performed with the VARIMAX rotation option. As a result, six factors as exogenous variables and three factors as endogenous variables are extracted successfully. For the further establishment of reliability, convergent validity, and discriminant validity of the multi-item scales, confirmatory factor analysis (CFA) and EFA are both conducted as Gerbing and James (1992) recommended. The results of this EFA and CFA study are presented in table 3. In the CFA, major fit indicators such as GFI, CFI, SRMR, RMSEA are in the recommended area. The internal validity of the measurement model are examined by the composite reliability and AVE (Fornell and Larcker, 1981). All the composite reliabilities are greater than the recommended level of 0.60 (Nunnally and Bernstein, 1994) and the AVEs, except for innovativeness (.487), are greater than 0.50 (Bagozzi and Yi 1988). Also, all items' loadings indicate significant t-values, which means satisfaction of convergent validity. 
Table 2: Reliability And Validity

\begin{tabular}{|l|c|c|c|}
\hline Construct & Cronbach's $\alpha$ & Composite Reliability & Average Variance Extracted \\
\hline Innovativeness & .735 & .740 & .487 \\
\hline Optimism & .767 & .773 & .533 \\
\hline Discomfort & .626 & .633 & .376 \\
\hline Insecurity & .767 & .776 & .538 \\
\hline Responsiveness & .885 & .888 & .727 \\
\hline Smartness & .744 & .753 & .504 \\
\hline PEOU & .856 & .856 & .665 \\
\hline PU & .831 & .829 & .618 \\
\hline IU & .946 & .946 & .855 \\
\hline
\end{tabular}

\section{RESULTS}

The hypothesized relationships are tested using the technique of structural equation modeling (SEM). The test results in the chi-square statistics of $793.237(\mathrm{p}=.000, d f=300)$. Although the chi-square value is significant, this statistics is sensitive to sample size and model complexity. Other statistics such as GFI, CFI, SRMS, RMSEA are more appropriate for assessing the fit of the model (Bagozzi and Yi, 1988). In this testing, GFI(.91), CFI(.94), SRMR(.07), RMSEA (.05) indicate satisfactory model fits. Therefore, further analysis of the relationship between the constructs is conducted. The results are presented in table 4. According to the results, except for the H8, hypothesis $\mathrm{H} 1$ through $\mathrm{H} 9$ are valid with less than $0.01 \mathrm{p}$-values.

Table 3: Overall Fits Of Model

\begin{tabular}{|l|c|c|}
\hline Fit Index & Recommended Critical Value* & Result \\
\hline Chi-square/df & $<=3.0$ & 2.64 \\
\hline GFI & $>=0.9$ & 0.91 \\
\hline AGIF & $>=0.8$ & 0.89 \\
\hline CFI & $>=0.9$ & 0.94 \\
\hline NFI & $>=0.9$ & 0.91 \\
\hline SRMR & $<=0.08$ & 0.70 \\
\hline RMSEA & $<=0.05$ & 0.05 \\
\hline
\end{tabular}

* Hu \& Bentler, 1999

Table 4: Hypothesis Testing

\begin{tabular}{|l|c|c|c|c|c|}
\hline Hypothesis & Estimate & Standardized Estimate & S.E & C.R & P \\
\hline H1. innovativeness -> ease of use & 0.196 & 0.180 & 0.057 & 3.462 & 0.000 \\
\hline H2. optimism -> ease of use & 0.378 & 0.356 & 0.055 & 6.870 & 0.000 \\
\hline H3. discomfort -> ease of use & $(0.794)$ & $(0.437)$ & 0.129 & $(6.157)$ & 0.000 \\
\hline H4. insecurity -> ease of use & 0.192 & 0.169 & 0.059 & 3.246 & 0.001 \\
\hline H5. smartness -> usefulness & 0.471 & 0.517 & 0.051 & 9.158 & 0.000 \\
\hline H6. responsiveness -> usefulness & 0.133 & 0.168 & 0.035 & 3.831 & 0.000 \\
\hline H7. ease of use -> usefulness & 0.250 & 0.285 & 0.037 & 6.726 & 0.000 \\
\hline H8. ease of use -> intention & 0.001 & 0.001 & 0.060 & 0.023 & 0.981 \\
\hline H9. usefulness -> intention & 0.752 & 0.582 & 0.076 & 9.889 & 0.000 \\
\hline
\end{tabular}

Finally, correlation coefficients among the independent exogenous variables are examined for the purpose of multicollinearity problem. They are below the recommended cutoff values (0.7) (Hair et al., 2010). Table 5 presents the correlation coefficients.

Table 5: Correlations Among The Exogenous Variables

\begin{tabular}{|l|c|c|c|c|c|}
\hline & Innovativeness & Optimism & Discomfort & Insecurity & Responsiveness \\
\hline Innovativeness & & & & & \\
\hline Optimism & .307 & & & & \\
\hline Discomfort & -.096 & -.222 & & & \\
\hline Insecurity & -.270 & -.205 & .329 & & \\
\hline Responsiveness & .247 & .247 & -.251 & -.273 & \\
\hline Smartness & .313 & .582 & -.128 & -.130 & .482 \\
\hline
\end{tabular}

Copyright by author(s); CC-BY 


\section{DISCUSSION AND CONCLUSION}

The findings of this study have significant implications on user behaviors regarding NFC mobile payment. This study uses an integrated model of TR and TAM, i.e., TRAM. Most previous researches on TRAM use dual paths, where the four constructs of TR influence both perceived ease of use and perceived usefulness of TAM. In the TRAM model of this study, four personality TR constructs can influence the perceived ease of use and technological characteristics can influence the perceived usefulness independently.

In the result, the four constructs of TR have significantly impact the perceived ease of use and two of the technological characteristics of NFC mobile payment also have a significant impact on perceived usefulness. The perceived usefulness significantly affects the intention to use. The path between intention to use and perceived ease of use is not acceptable with a p-value greater than significance level .05. For the success of the NFC mobile payment system, emphasizing on convenience of NFC mobile payment is not good enough and it would be better to let smartphone users know about the benefit and value of NFC mobile payment.

This study also suggests important practical implications for mobile payment. Due to the early stage of NFC mobile payment, it is one of the first of its kind, giving empirical analysis to understand the customers' behavior for the adoption of NFC mobile payment systems. While the NFC mobile payment is struggling in most of the world, Korea became a pioneer in rolling out the NFC mobile payment technology. Global mobile industries pay attention to whether Korean mobile users accept the new payment service or not. As the Korean young adults show a high and fast adoption rate for new technologies like smartphones and mobile internet, the NFC mobile payment is also expected to be another success story.

In Korea, NFC providers' marketing strategies seem to focus on only convenience of NFC payment such as non-swiping cards and auto transaction with a short-range wireless technology. From the results of this paper, perceived ease of use without strong perception of usefulness might not efficiently push smartphone users to engage in the use of their NFC payment.

Since TR is determined by general perception about a new technology, it is individually predetermined and it is not easy to change. Therefore, even if NFC is an emerging new technology, each individual's TR toward NFC mobile payment may not change abruptly. To promote a use of NFC mobile payment, it might be a good idea to find a group of users who favor the NFC mobile payment, and then expand target users from the group to normal smartphone users.

This study also has several limitations. Even if the study is a pioneer in the NFC mobile payment service, it focuses on only Korean college students. According to the recent surveys about mobile payment methods in Korea (Shin et. al, 2014), the percentage of respondents using a NFC mobile payment is only $28.1 \%$, which means that this study measured not the experience of NFC mobile payment but their expectations of it. Google Android and Apple iOS has dominated smartphone operating system markets over the past few years. While Android accepts NFC technology in its early version, iOS does not accept it until the recent version of 6.0. According to the report for mobile market share (iCrossing, 2012), in Korean market, 90\% of smartphones have Android operating system and only $9 \%$ of them have iOS. Therefore, the result of this study cannot be directly transferred to other countries because of different market shares of smartphone platforms.

\section{AUTHOR INFORMAITON}

Seungjae Shin received a Ph.D. in information sciences (2003) at the University of Pittsburgh and a Ph.D. in Industrial and Systems Engineering (2013) at Mississippi State University. He is currently an Associate Professor of Information Systems and Supply Chain Management at Mississippi State University, Meridian. His research areas are telecommunications industry analysis and logistics.

Won-jun Lee received a Master degree (1996) and a Ph.D. in Marketing (2005) at the Seoul National University. $\mathrm{He}$ is currently an Associate Professor of Business Management at Cheongju University in Korea. His research areas are technology marketing, consumer behavior and e-WOM communication. 


\section{REFERENCES}

1. Agarwal, S., Khapra M., Uchat N., and B. Menezes. (2007). Security Issues in Mobile Payment Systems, Proceedings of the 5th International Conference on E-Governance, Hyderabad, India.

2. Bagozzi, R., and Yi Y. (1988). On the evaluation of structural equation models, Journal of the Academy of Marketing Science, 16(1), 74-94.

3. Banwari, M., and Lassar, W. M. (1996). The Role of Personalization in Service Encounters, Journal of Retailing, 72(1), 95-110.

4. Brown, C. (2011). Korean National NFC Alliance Aims to Create a Billion Dollar Business Opportunity, Retrieved from http://www.nfcworld.com/2011/06/06/37845/korea-national-nfc-alliance-to-create-billiondollar-business-opportunity/

5. Chang H. H., and Wang, I. (2008). TAM and Flow Theory for Investigating on User Communication Behavior in Computer Mediated Environments, European Advances in Computer Research, 8, 158-159.

6. Chen, L. (2008). A Model of Consumer Acceptance of Mobile Payment, International Journal of Mobile Communication, 6(1), 32-52.

7. Chuttur, M. (2009). Overview of the Technology Acceptance Model: Origins, Developments and Future directions, Indiana University, USA. Sprouts: Working Papers on Information Systems, 9(37). http://sprouts.aisnet.org/9-37

8. Davis, F. D. (1989). Perceived Usefulness, Perceived Ease of Use, and User Acceptance of Information Technology, MIS Quarterly, 13, 319-340.

9. Ezell, S. (2009). Contactless Mobile Payment., Retrieved from http://www.itif.org/files/2009-MobilePayments.pdf

10. Fornell, C., and Larcker, D. F. (1981). Evaluating structural equation models with unobservable variables and measurement error, Journal of Marketing Research, 39-50.

11. Fournier, S. (1998). Consumers and their brands: Developing relationship theory in consumer research, Journal of Consumer Research, (24), 343-373.

12. Furnham, A. (2004). Management and Myths: Challenging business fads, fallacies and fashions, Basingstoke: Palgrave Macmillan.

13. Gerbing, D. W., and Anderson, J. C. (1992). Monte Carlo evaluations of goodness of fit indices for structural equation models, Sociological Methods and Research, 21(2), 132-160.

14. Gerpott, T. and Kornmeier, K. (2009). Determinants of Customer Acceptance of Mobile Payment Systems, International Journal of Electronic Finance, 3(1), 1-30.

15. Godoe P. and Johansen, T.S. (2012). Understanding Adoption of New Technologies: Technology Readiness and Technology Acceptance as an Integrated Concept, Journal of European Psychology Students, 3, 38-52.

16. Ha, S. and L. Stoel, (2009). Consumer e-shopping acceptance: antecedents in a technology acceptance model, Journal of Business Research, 62(5), 565-571.

17. Hair, J.F., Black, W.C., Babin, B.J., and Anderson, R.E. (2010). Multivariate Data Analysis, 7e., Upper Saddle River, NJ: Prentice Hall.

18. Hsu, C., Wang, C., and Lin, J. C. (2011). Investigating Customer Adoption Behaviors in Mobile Financial Services, International Journal of Communication, 9(5), 477-494.

19. Hu, L. z. \& Bentler, P. M. (1999). Cut off criteria for fit indexes in covariance structure analysis: conventional criteria versus new alternatives. Structured Equation Modeling, 6, 1-55.

20. iCrossing. (2012) Mobile Market Share, Retrieved from http://connect.icrossing.co.uk/2012-mobilemarket-share-infographic_7962

21. Kang, H., Hahn, M. Fortin, D. R. Hyun, Y. J. and Eom, Y. (2006). Effects of Perceived Behavioral Control on the Consumer Usage Intention of e-coupons, Psychology \& Marketing, 23, 841-864.

22. Kim, D., and Ammeter, A. P. (2008). Examining Shifts in Online Purchasing Behavior: Decoding the 'Net Generation', Academy of Information and Management Science, 12 (1), 7-12.

23. Lam, S. Y., J. Chiang, and A. Parasuraman. (2008), The Effects of the Dimensions of Technology Readiness on Technology Acceptance: An Empirical Analysis, Journal of Interactive Marketing, (22:4), pp 19-39.

24. Lin, C., Shih, H. and Sher, P. J. (2007). Integrating Technology Readiness into Technology Acceptance: The TRAM Model, Psychology \& Marketing, 24(7), 641-657. 
25. Liu, Y., Wang, S. and Wang, X. (2011). A Usability-centered Perspective on Intention to Use Mobile Payment, International Journal of Mobile Communications, 9(6), 541-562.

26. Meijer, C. R.W. \& Bye, J. (2011). The increasing adoption of mobile payments in Europe and remaining challenges to growth, Journal of Payments Strategy and Systems, 5 (3), 273-288.

27. Moon, J. Y. and Kim, Y. G. (2001). Extending the TAM for a World-Wide-Web Context, Information and Management, 38, 217-230.

28. Nam, S., Chiang, J. and Parasuraman, A. (2008), The Effects of the Dimensions of Technology Acceptance: An Empirical Analysis, Journal of Interactive Marketing, 22(4), 19-39.

29. Niesen. (2013). The Mobile Consumer, A Global Snapshot, Retrieved from http://www.nielsen.com

30. Nunnally, J. C. (1967). Psychometric Theory, New York: McGraw-Hill.

31. Nunnally, J. C., Bernstein, I. H. (1994). Psychometric theory, New York: McGraw-Hill.

32. Oblinger, D. and Oblinger, J. (2005). Educating the Net Generation, Retrieved from http://www.educause.edu/ir/library/pdf/pub7101.pdf

33. Parasuraman, A. (2000). Technology Readiness Index(TRI): A Multiple-item Scale to Measure Readiness to Embrace New Technologies, Journal of Service Research, (2), pp 307-320.

34. Pechman, C., and Ratneshwar, S. (1994). The Effects of Antismoking and Cigarette Advertising on Young Adolescents' Perceptions of Peers Who Smoke, Journal of Consumer Research, 21, 236-251.

35. Pousttchi, K., Wiedemann, D. G. (2007). What Influence Consumers' Intention to Use Mobile Payments?, 6th Annual Global Mobility Roundtable, in Los Angeles.

36. Rijsdijk, S. A., and Hultink, E. J. (2009). How Today's Consumers Perceived Tomorrow's Smart Product, The Journal of Product Innovation Management, 26, 24-42.

37. Schierz, P.G., Schilke, O. and Wirtz, B. (2010). Understanding Consumer Acceptance of Mobile Payment Services: An Empirical Analysis, Electronic Commerce Research and Applications, 9(3), 209-216.

38. Shih, C., and Venkatesh, A. (2004). Beyond Adoption: Development and Application of a Use-Diffusion Model, Journal of Marketing, 68, 59-72.

39. Shim, J. P., Shin, S., and Weiss, M. B. (2006). Digital Multimedia Broadcasting (DMB): Standards, Competition, and Regulation in South Korea, Journal of Information Technology Theory and Application, 8(2), 69-81.

40. Shin, S., Lee, W., and Odom, D. (2014). A Coparative Study of Smartphone User's Perception and Preference towards mobile payment Methods in the U.S. and Korea, TBA.

41. Stalfors P., and Nykvist, R. (2011). Consumer Acceptance of Mobile Payment Services, Retrieved from https://gupea.ub.gu.se/bitstream/2077/25614/3/gupea_2077_25614_3.pdf

42. Varshney, U. and Vetter, R. (2002). Mobile Commerce: Framework, Applications and Networking Support, Mobile Networks and Applications, 7(3), 185-198.

43. Venkatesh, V. and Davis, F. D. (1996). A Model of the Antecedents of Perceived Ease of Use: Development and Test, Decision Sciences, 27, 451-481.

44. Venkatesh, V. (2000). Determinants of Perceived Ease of Use: Integrating Control, Intrinsic Motivation, and Emotion into Technology Acceptance Model, Information systems Research, 11(4), 342-365.

45. Venkatesh, V. and Goyal, S. (2010). Expectation Disconfirmation and Technology Adoption: Polynomial Modeling and Response Surface Analysis, MIS Quarterly, 34(2), 281-303.

46. Walczuch, R., Lemmink, J. and Streukens, S. (2007). The Effect of Service Employees' Technology Readiness on Technology Acceptance, Information \& Management, 44, 206-215.

47. Warshaw, P. R., and Davis, F. D. (1985). Disentangling Behavioral Intention and Behavioral Expectation, Journal of Experimental Social Psychology, 21(3), 213-228.

48. Wu, X., and Fan J. (2010). Empirical Research of Mobile Payment User Behavior Based on Perceived Risk, International Conference on Communication Systems, Networks and Applications 2010. 


\section{NOTES}

